ditions as do those of medicine or engineering for example. And the men who are to solve them must have just as broad and thorough a fundamental training as the researcher in medicine or engineering. Moreover, apart from his research, the technical agriculturist has to face just as many situations requiring broad education and culture as have any other professional men.

Now the medical colleges require the equivalent of two years of arts work with specified large credits in the sciences, before admission is granted to the purely medical studies. Some indeed require full arts graduation and all medical authorities advise graduation in arts even where they do not require it. All this is required of those who are to become only general medical practitioners. Much more is necessary for the research man.

Similar conditions are found in regard to the training for other professions. In engineering, law, divinity, a broad fundamental training is considered necessary and is generally required. At the recent Canadian universities conference held at Quebec a resolution was unanimously adopted calling for large increases in English, history, economics and particularly fundamental science in the training of engineers. The ideal of all educationists in these professions is to secure complete arts graduation before admission to professional studies, and failing that a large and specified amount of arts work.

In my opinion the professional agriculturist should have just as thorough a pre-professional training. This is true not only for the researcher in agricultural problems but also for agricultural teachers in schools or colleges, district representatives, inspectors, laboratory men and various administrators.

In those institutions which include both arts and agricultural colleges, it should be easy to arrange for such training. The pre-agricultural students should be taught in the same classes as the pre-medical students, or preengineering students, or straight arts students. In other places the students may not be given the formal arts classes but he should get the equivalent of them in a thorough broad train- ing during the first two years. In all cases, if he is to benefit by his work, complete matriculation should be demanded before the student is permitted to enter. It is essential pedagogically that the basic subjects be taught before the student takes up the professional ones. They should certainly not be tacked on after the student has taken his professional work. This will involve an almost complete separation of the courses for technical agriculturists from those for the men who are to return to the farms. In short our ideal should be to bring our professional agricultural training abreast of our training for other professions by requiring as pre-agricultural study a large amount of, and as soon as possible complete, arts work. Only in this way can we secure a supply of properly trained research men as well as of other technical agriculturists.

The educational aspect of the relationship also involves the question of graduate work which is a very passing one in Canada. But as that is to be dealt with by another speaker, I shall refrain from discussing it.

I said at the outset that I would not attempt a comprehensive treatment of the subject-in spite of the time I have taken. I have tried to emphasize four respects' in which, in my opinion, the relation of scientific research to agriculture is peculiarly important in Canada at the present time. They may be designated (1) Foundation, (2) Cooperation, (3) Remuneration and (4) Education.

W. P. THOMPSON

UNIVERSITY OF SASKATCHEWAN

\section{LIMITATIONS OF EXPERIMENT IN EXPLAINING NATURAL HABIT, AS ILLUSTRATED BY THE DIURNAL MIGRATION ${ }^{1}$}

THE general facts about the diurnal distribution of plankton organisms are these: at night there is greater abundance of a given species at higher levels and less abundance at

1 A paper read at the meeting of the Western Society of Naturalists, Pasadena, California, June 20,1919 . 
lower levels; by day the abundance is less at higher levels and greater at lower levels. One form may have a vertical range from the 100 fathom to the 200 fathom mark and another may range from the surface to 50 fathoms. The increase in numbers in the upper strata at night is believed to be due to upward movement of the animals from lower levels; the increase in numbers below the surface during the day is held to be due to descent from higher levels. The whole phenomenon is spoken of as diurnal migration.

The explanation of such movements has often been attempted. The one that has been most in vogue is based on change in direction of movement as some external condition is altered. That is, reactions are involved in the varying relations between the environment and the distribution of the organisms. Since the vertical movement is rhythmic and corresponds to the change between day and night it seems reasonable to suppose that the direction of movement changes as the light intensity changes; the animals might move toward a light of low intensity and away from one of higher intensity. Again, evidence has been presented showing that the geotropism of some forms changes with the light intensity. It has been thought, furthermore, that alterations in temperature or salinity are accompanied by reversals of direction of movement, either with relation to a source of light or to gravity. There is reason for this view since the organisms actually pass through different temperatures and salinities as they move up and down.

The foregoing possibilities all exist. But such questions as these have arisen: How generally do the possibilities apply? Are they applicable to all plankton animals? Do reversals in direction of movement really take place as it is possible they may? An investigation of such questions occupied the time of the writer for a year at the Scripps Institution. The reactions of different plankton animals were studied, with the special point in mind of applying the results to the diurnal migration problem. The attempt was made to find out for each species whether movement is toward or away from a weaker or stronger light; whether specimens ascend or descend in darkness as compared with diffuse light; whether locomotion in a vertical direction is toward or away from a light at the top of a column of water; whether direction of movement under any of the foregoing conditions changes if the temperature or salinity is changed.

It would be out of place to go into details bere, but it should be said that experimental data that may show why the diurnal movement takes place were not obtained except in the case of the chætognath, Sagitta bipunctata; this form is one of seven that were used consistently. There is good evidence from field records that all of the species used in the experiments perform the diurnal migration. Furthermore, the field data from the San Diego region relating to one of the copepods and to Sagitta have been more completely worked out than for any other marine plankton animals anywhere. The relation between abundance or scarcity of these forms and external conditions revealed by collecting records, is thoroughly well known.

, While the experiments that have been mentioned did not show how behavior in the laboratory is related to diurnal migration, they did bring to light matters that are certain to affeot the interpretation of experimental results as applied to an explanation of a natural habit. It may be suggested, also, that these matters will probably enter into any study of reactions whose purpose is to discover the reasons for a given sort of behavior under natural conditions. The following are the points which seem to be of general importance.

1. Specificity in behavior. There is no doubt that a general explanation of diurnal migration is possible only when the different species have been studied in the laboratory; and it may not be possible even then to account for the diurnal migration as a general occurrence in the plankton. Various animals perform the migration together, but the reasons are different for the different forms. "Blanket explanations" have been given which are misleading because the reaction differences between species were not appreciated. One should not attempt to account for the vertical migration 
of a copepod on the same basis that one explains a similar habit in a chætognath.

1 2. There is something connected either with the removal of specimens from the sea or their retention in the laboratory, or with both, that affects the responses in some cases. The relation between the behavior in the laboratory and that in the sea is consequently obscured. For example, the copepod, Calanus finmarchicus, can be taken at twenty fathoms during the day. When removed to the laboratory these animals are positive to light for about an hour on the average but become negative and remain so persistently. Is it not obvious that such a reversal makes it difficult to know how to apply experimental results toward explaining the migration? This kind of thing did not appear in all the species that I used, but it oertainly should be looked for in all cases.

3. Specimens of the same species, but obtained from different locations or habitats, show noteworthy differences in behavior. A good example of this is found in the reactions of a copepod, Acartia tonsa. If animals are used that were obtained at the surface they move toward the light, and they ascend in diffuse light though they descend in darkness. But if the specimens were obtained from deeper water (60-100 feet) they move away from the light and descend both in diffuse light and in darkness.

Suppose that one is attempting to explain the diurnal migration of Acartia. The results of experiments with surface animals would lead one to expect to find the animals at the surface during the day and at lower levels at night. While they may be found at the surface by day at times, we have thousands of collections which show that these copepods are much more abundant at the surface at night. It depends on the particular animals collected whether it shall be said that Acartia tonsa as a species is positive or negative to light. It is worth noting in this connection that specimens of $A$. tonsa from deep water, if left in the laboratory for several hours, will react as surface animals do.

1 4. Need of experimental and field data to- gether. It does not seem possible that the facts of nor the reasons for the diurnal migration (or any other natural habit) can be obtained without both laboratory and field studies. The results of work in the field will show what the animals do in their natural surroundings, while experimental work may show why they act as they do. Experiments are incapable of revealing what occurs in a natural habitat, unless it is possible to duplicate nature in the laboratory and at the same time secure experimental control. One can hardly do better in this connection than to quote what another has written:

What right has one to assume that the reactions of an animal taken rudely from its natural habitat and as rudely imprisoned in some improvised eage are in any scientific sense an expression of its nor. mal behavior either physical or psychicals Is it within the range of the calculus of probability that conclusions drawn from observations made upon an animal in the shallow confines of a fingerbowl, but whose habitat has been the open sea, are trustworthy? . . . Laboratory appliances are indispensable. But at the same time it must be recognized that they are at best but artificial makeshifts whose values, unless constantly checked by appeals to nature, must be taken at something of a discount.1

Such statements as the foregoing can not apply to experimental procedure that attempts to ascertain what animals can do, for example, or how sensitive they are to stimulation. Strictly physiological studies are both necessary and important and their brilliant results more than justify them. But in such methods of working the agent is emphasized rather than the organism, and the aim is to "work out the physics and chemistry of biological phenomena." 2 When, however, the organism is the chief interest, the natural history of the organism must be known if we are to study nature instead of things in a laboratory. Laboratory studies are of no more importance than those made in the field if one's object is to get

1 Charles W. Hargitt, Jour. An. Behav., 2, pp. 51-52, 1912.

2 H. S. Jennings, Amer. Jour. Psych., 21, p. 353, 1910. 
knowledge of living things as they are in nature.

SCRIPPS INSTITUTION OF THE

Calvin O. Esterly

UnIVERSity of CALIFornia

\section{SCIENTIFIC EVENTS \\ THE BRITISH NATIONAL PHYSICAL LABORATORY}

The British Department of Scientific and Industrial Research announces that the report of the National Physical Laboratory for the year 1919 has now been issued. It contains among other matter the report of the executive committee for the year 1919, the statement of work proposed for the year 1920-21, a list of papers published by the laboratory during the years 1917-18 and 1919 or communicated by members of the staff to scientific societies or to the technical journals, and the report of the director for the year 1919 .

Some particulars of special work done during the war which it was previously necessary to treat as confidential are included, and the descriptions of such work now given will, it is hoped, be found of interest. This special work includes gauge testing carried out for the ministry of munitions, and a large number of special researches carried out by the electricity and metallurgy department and by the William Froude national tank.

The heads of the various departments give accounts of the recent work of the laboratory as follows:

Physics Department.

I. Heat:

(a) High Temperature and General Work,

(b) Thermometer Testing,

II. Optics.

(c) Oil Apparatus Testing.

III. Radium and $\mathrm{X}$ Ray work.

IV. Tide Prediction.

V. Library.

Electricity Department.

Metrology Department.

Engineering Department.

Aerodynamics Department.

Metallurgy Department.

The William Froude National Tank.
THE FAIRPORT FISHERIES BIOLOGICAL STATION

THE new building will be dedicated on October 7. The formal exercises will be divided into two parts-a forenoon session devoted to the immediate service of the station to industries and an afternoon session to consider the functions of the station in the advancement of science and the possibilities of further economic applications of its work. At each session there will be a principal address and three or four brief talks or messages. The speakers will be men of distinction in science and in public service. Opportunity will be afforded for inspection of the establishment, and, at suitable times to be appointed on October 7 and 8 , scientists, state officers and other guests in attendance will be invited to confer regarding its purposes and work.

The reservation is on the Mississippi River, twenty miles below Davenport, and nine miles above Muscatine, Iowa. It comprises 60 acres of ground extending from the bank of the river to an elevation of about 200 feet above the river. Principal buildings are the biological laboratory, tank house, pumping station, hatchery (temporary laboratory), shell-testing plant and cottages. There are two water systems-unfiltered river water with storage reservoir of 2,000,000 gallons capacity and filtered water with gravity sand filter and low and high pressure cisterns. There are thirtyone ponds, of which nine are concrete-lined, while the remainder have walls and bottoms of natural earth.

The former laboratory building, opened in 1914, was of frame construction, about 100 by 50 feet, with two full stories, half basement and attic. It was destroyed by fire December 20,1917 , with the loss of a valuable library and many scientific records and specimens. The new building has the same location and approximately the same external dimensions as the old, but experience gained during occupancy of the first building and the resourcefulness and skill of the architect, have combined to make the new one superior in available space, convenience and serviceability. 